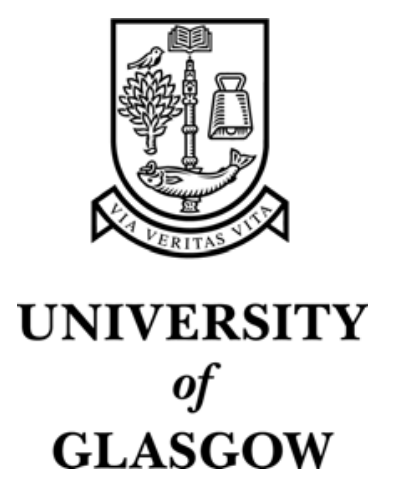

Colby, R.S. and Mottier, F.M. and Miller, T.J.E. (1996) Vibration modes and acoustic noise in a four-phase switched reluctance motor. IEEE Transactions on Industry Applications 32(6):pp. 1357-1364.

http://eprints.gla.ac.uk/archive/00002842/ 


\title{
Vibration Modes and Acoustic Noise in a Four-Phase Switched Reluctance Motor
}

\author{
Roy S. Colby, Senior Member, François M. Mottier, and Timothy J. E. Miller, Fellow
}

\begin{abstract}
Acoustic noise in the switched reluctance motor (SRM) is caused primarily by the deformation of the stator lamination stack. Acoustic noise is most severe when the periodic excitation of the SRM phases excites a natural vibration mode of the stack. The natural vibration modes and frequencies of a four-phase, 8/6 SRM are examined. Structural finite element analysis is used to compute the natural modes and frequencies. Impulse tests on the stator stack verify the calculations and show which modes are excited. Heuristic arguments are developed to predict the operating conditions that will excite the natural modes. Measurement of vibration while the machine is under load shows which operating conditions excite the natural modes and verifies the predictions. An approximate formula is derived to predict the frequency of the fundamental vibration mode in terms of lamination dimensions and material properties. The formula is validated by comparison with finite element calculations for several laminations, and hence is shown to be useful in design trade-off studies.
\end{abstract}

Index Terms-Acoustic noise, noise, switched reluctance, and vibration

\section{INTRODUCTION}

\section{A. History of Noise in the SR Motor}

A LTHOUGH patented in 1972 [1], the switched reluctance motor (SRM) did not become prominent in research and development until after Lawrenson's seminal paper of 1980 [2], and it is only in recent years that serious attempts have been made to analyze its acoustic noise and to reduce it to an acceptable level. During the 1980's a small number of commercial SR products-and an even larger number of laboratory prototypes-gave rise to a widespread perception that the SRM is "inherently noisy". Along with this perception was the related impression that the SRM has inherently high torque ripple.

Although there is plenty of anecdotal evidence to suggest that the SRM is noisy and has high torque ripple, it is easy to forget that noise and torque ripple are present in ample quantities in single-phase induction motors, universal ac commutator motors, stepper motors, and some inverter-fed

Paper IPCSD 96-32, approved by the Electric Machines Committee of the IEEE Industry Applications Society for presentation at the 1995 IEEE Industry Applications Society Annual Meeting, Lake Buena Vista, FL, October 8-12. Manuscript released for publication May 13, 1996.

R. S. Colby is with the United Technologies Research Center, East Hartford, CT 06108 USA.

F. M. Mottier is a consultant in West Hartford, CT 06117-2034 USA.

T. J. E. Miller is with the Department of Electronics and Electrical Engineering, University of Glasgow, Glasgow G12 8LT, U.K.

Publisher Item Identifier S 0093-9994(96)07071-5. induction motors; and that effective solutions have taken a long time to develop, if they have developed at all. At the same time, there is nothing to prove that the SRM cannot be made acceptably smooth and quiet, and since research on the SRM is clearly far from exhausted, it would be premature to dismiss it on grounds of excessive noise.

The first systematic study of SRM noise was published by Cameron, Lang, and Umans [3]. They used basic engineering theory and a series of carefully designed experiments to show that the main sources of noise are the "ovalization" or modal deflection of the stator back-iron as a ring, and the lateral rocking of the stator poles. This study pointed out the importance of resonant vibratory modes, so that the use of the counter-excitation principle by $\mathrm{Wu}$ and Pollack [4] appeared to be both rational and timely. $\mathrm{Wu}$ and Pollack showed that greater noise suppression could be achieved by half-cycle counter-excitation at the turn-off angle in each phase, than at the turn-on angle. Other ameliorative control measures were studied by other authors, not only in connection with acoustic noise but also to minimize torque ripple: see, for example, Blaabjerg [5], le Chenadec [6]. Most of these authors concerned themselves with current waveshaping or other modifications of the electronic control strategy, and few of them gave much guidance in the basic mechanical design of the SRM.

The origin of acoustic noise within electric motors is an old topic, and indeed the nature and origin of the noise- and torque- producing forces has been central in the development of SR theory since the earliest times (see, for example, J. V. Byrne [7] and more recently, Takayama [8]). Most early works were concerned with maximizing the torque per ampere-possibly even by methods that would inadvertently maximize the noise level. A survey of noise sources within the SRM was published by Hendershot [9], and an experimental and theoretical evaluation of radial forces, including unbalanced forces, was published by Miller [10]. Besbes et al. [13] calculated magnetic forces and mechanical frequencies in the stator of a three-phase 6/8 SRM and verified the calculations by experiment. A practical procedure for calculating the stator radial vibration of hybrid stepping motors was published by So et al. [11]; this method could readily be adapted to the SRM. Although So used force distributions calculated from basic geometry and winding and electromagnetic parameters, the "transfer mobility spectra" which he used to represent the mechanical compliance and resonances were measured, and he gave no indication of how to calculate them. 


\section{B. Overview}

This paper describes an analytical and experimental study of the vibration and acoustic noise in a 4-phase, 8/6 switched reluctance motor. Structural finite element analysis (FEA) is used to predict the mode shapes and frequencies of stator vibration and heuristic arguments are developed to indicate which operating conditions will excite the different modes. Experimental results validate the predictions, both for mode shape and frequency, and for the operating conditions that excite the natural modes. An approximate formula is derived to predict the frequency of the dominant vibration mode as a function of lamination dimensions and material properties. The formula is validated by comparison with finite element calculations and with experiment. The formula may be used in design trade-off studies to assess the noise impact of design modifications.

\section{NAtural Vibration Modes of the 4-Phase Motor}

\section{A. Calculation of Mode Shapes}

The subject of the present study is a four-phase, eight-statorpole, six-rotor-pole SRM, sized for a NEMA 56 frame. The stator lamination is a rounded octagon, with a mean outside diameter of $159.5 \mathrm{~mm}$, yoke thickness $16.5 \mathrm{~mm}$, and bore diameter $83 \mathrm{~mm}$.

Mode shapes and resonant frequencies were computed with the ALGOR FEA program on a ' $486 \mathrm{PC}$. The goal of the modeling was the calculation of the set of eigenmodes in which the laminations move in unison in the plane of the lamination. Eigenmodes of the lamination stack in which the adjacent laminations would move against each other, such as twisting of the poles about an axis in the lamination plane, were excluded from consideration. For this reason the lamination was modeled from two-dimensional (2-D) elements, whose deflection is constrained to in-plane motion. The authors of [3] showed that the vibrations were fairly uniform along the length of the stator stack, hence a 2-D analysis is justified. Material parameters are density $\rho=7866 \mathrm{kgm} / \mathrm{m}^{3}$, elasticity $E=207 \mathrm{GPa}$, and Poisson's ratio $\nu=0.3$.

The computed mode shapes are presented graphically in Fig. 1(a)-(i), which shows the first nine eigenmodes and their associated frequencies. The normal outline of the lamination is shown in a dashed line for reference in each illustration.

\section{B. Excitation of Natural Modes}

Normal SRM operation is characterized by large radial forces on opposite poles, which tend to deform the stator into an oval. A vibration mode will be excited when the radial forces on the stator poles coincide with the natural vibration. Three modes are characterized by such opposite radial motion of opposite poles. These modes are the secondorder cylindrical mode shown in Fig. 1(a), the fourth order mode shown in Fig. 1(d), and the uniform radial mode of Fig. 1(e). Cameron et al. [3] found that these modes are responsible for the majority of the acoustic noise from the motor.
The torque in the SRM exerts moments on opposite pairs of stator teeth, tending to bend the teeth and deform the stator. Two of the vibration modes are characterized by such bending of the stator teeth, namely the third mode of Fig. 1(c), and the ninth mode of Fig. 1(i). These modes may possibly be excited at certain speeds by the pulsed nature of SRM torque. An additional mode, shown in. Fig. 1(g), is characterized by a combination of radial motion and twisting of the poles, where opposite poles move in opposite directions.

The other modes, shown in Fig. 1(b), (f), and (h), are characterized by asymmetric vibration of the stator lamination stack, or parallel motion of opposite poles, and are unlikely to be excited by normal SRM operation.

It has been shown [12] that the fundamental mode 1a will be excited in the four-phase $8 / 6$ motor at speeds where the vibration frequency is an odd harmonic of the phase drive frequency. The vibration of phase a poles is $180^{\circ}$ out of phase from phase $c$ poles, and the excitations are similarly out of phase at odd harmonics of the drive frequency. By the same token the vibration of the fundamental mode will tend to be suppressed at speeds where the fundamental freqeuncy is an even harmonic of the drive frequency.

A similar, albeit more complicated, heuristic argument may be invoked to show that the fourth-order cylindrical mode of Fig. 1(d) will be excited when the mode frequency is at an alternate even harmonic of the drive frequency, e.g., at harmonic numbers $2,6,10,14,18,22$, etc. The fourth-order mode will tend to be suppressed at all other harmonics.

\section{MEASURED VIBRATION OF. SR MOTOR}

\section{A. Stationary Tests}

A vibration measurement with the rotor stationary was conducted to determine the frequencies of the natural modes. One phase of the motor was excited with a short voltage pulse, causing a triangular pulse of current, similar to the tests described in [4]. The pulse duration was $5 \mathrm{~ms}$, with a pulse repetition frequency of $30 \mathrm{~Hz}$. This allowed ample time for the vibrations to die out between pulses. The rotor poles were fully aligned with the driven phase resulting in maximum radial force and zero torque. The stator was instrumented with accelerometers at two locations: one was directly behind the pole of the driven phase, while the other was behind the adjacent phase, $45^{\circ}$ from the driven phase.

The output from the accelerometer behind the driven pole is shown in Fig. 2, along with the phase voltage waveform. (Only the last $1 \mathrm{~ms}$ of the $2.5-\mathrm{ms}$ duration positive voltage pulse is shown.) The phase current is rising while the voltage is positive, and falling while the voltage is negative. Fig. 2 shows that there is negligible vibration until the voltage is switched off, corresponding to the peak of the current waveform. This is consistent with the findings in [4] and [12] which showed that the greatest stator vibration was excited by turn-off of the current.

Two frequency components can clearly be seen in the waveform: the fundamental mode at about $1.6 \mathrm{kHz}$, with a higher frequency vibration of about $9 \mathrm{kHz}$ superimposed. A 


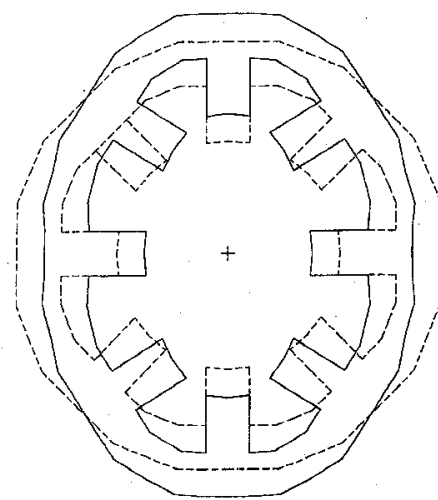

(a)

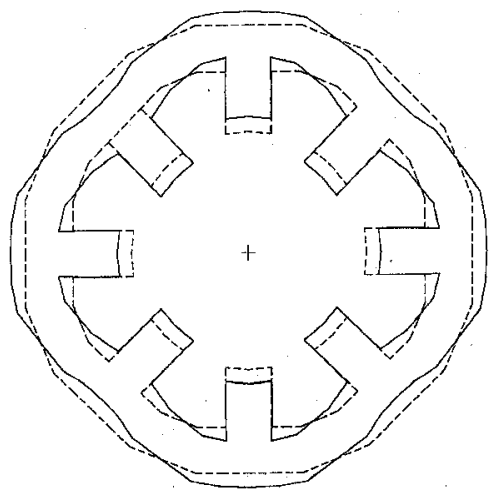

(d)

(g)

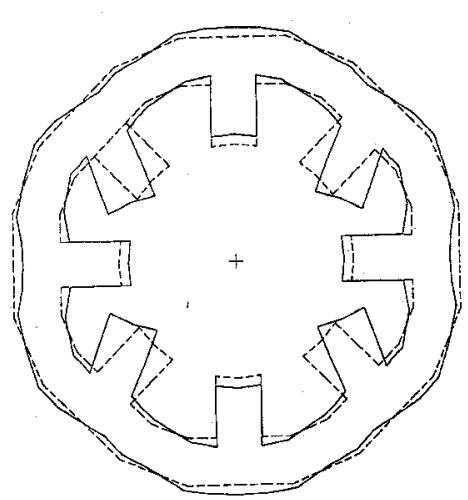

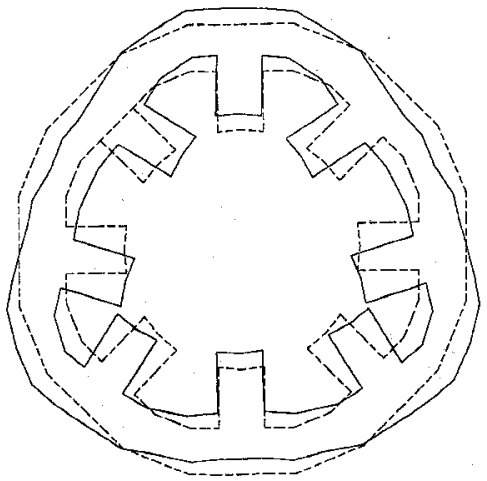

(b)

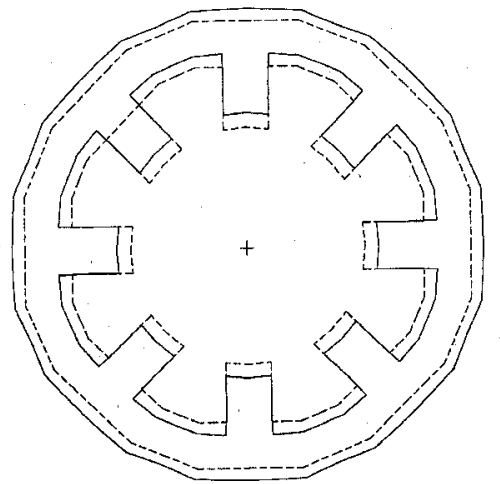

(e)

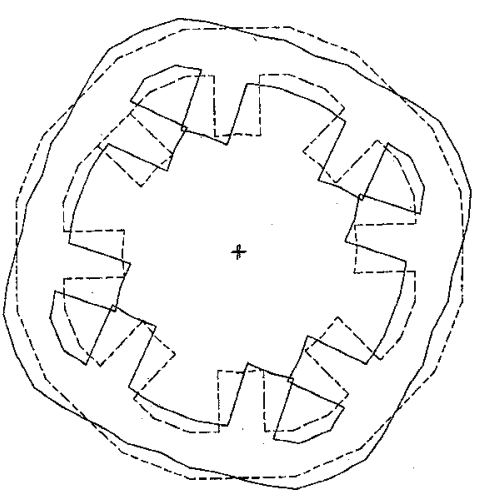

(c)

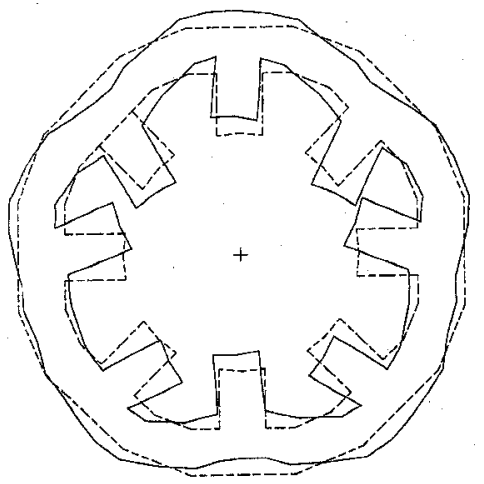

(f)

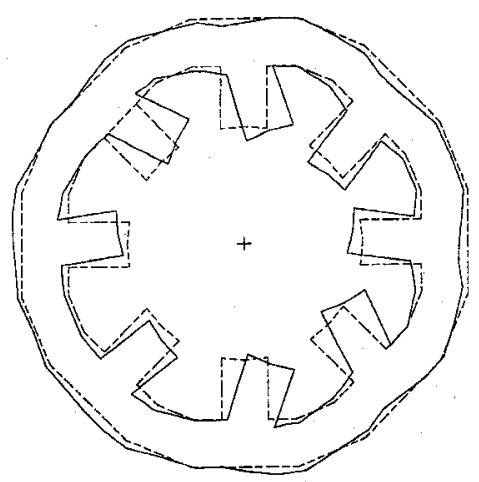

(h)

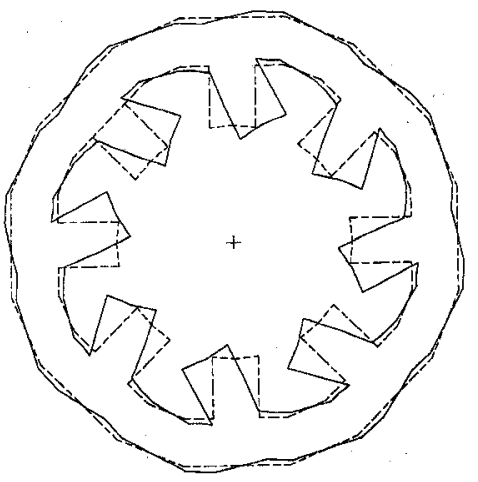

(i)

Fig. 1. (a) Mode at $1679 \mathrm{~Hz}$. (b) Mode at $4247 \mathrm{~Hz}$. (c) Mode at $6251 \mathrm{~Hz}$. (d) Mode at $8963 \mathrm{~Hz}$. (e) Mode at $9825 \mathrm{~Hz}$. (f) Mode at $10.7 \mathrm{kHz}$. (g) Mode at $12.4 \mathrm{kHz}$. (h) Mode at $12.8 \mathrm{kHz}$. (i) Mode at $14.0 \mathrm{kHz}$.

detailed look at the frequency content of the accelerometer signal is shown in Fig. 3. Here the sharp peak at $1.6 \mathrm{kHz}$ corresponds to the fundamental mode of Fig. 1(a), while the peak at $8.7 \mathrm{kHz}$ possibly corresponds to the fourth-order mode of Fig. 1(d). It can be noted that the mode of excitation used in this test will not excite the square mode of Fig. 1(c), as there is no moment (torque) exerted on the stator teeth. Additional energy is noted at $13 \mathrm{kHz}$, possibly corresponding to the hybrid mode of Fig. 1(g).

The accelerometer at the adjacent pole produced the time waveform shown in Fig. 4. This location is at a node of the fundamental mode, hence the waveform content at that frequency would be expected to be low. This is indeed the case, as can be seen in Fig. 4, where the high frequency at about $9 \mathrm{kHz}$ dominates. The frequency spectrum of this waveform is shown in Fig. 5, which shows that the contribution of the fundamental mode is reduced $8 \mathrm{~dB}$ relative to the higher frequency modes. It can also be noted that the resonant peak in the vicinity of $9 \mathrm{kHz}$ is much broader, suggesting that the fourth-order mode of Fig. 1(d), and the mode of Fig. 1(e) are both present. Additional energy is again noted at $13 \mathrm{kHz}$, suggesting the presence of the mode of Fig. 1(g).

It is noteworthy that the measured vibration mode frequencies are extremely close to the values predicted by the FEA. This confirms the essential accuracy and utility of the finite element method. Designers may use the structural FEA with confidence to predict natural modes of a particular design. 


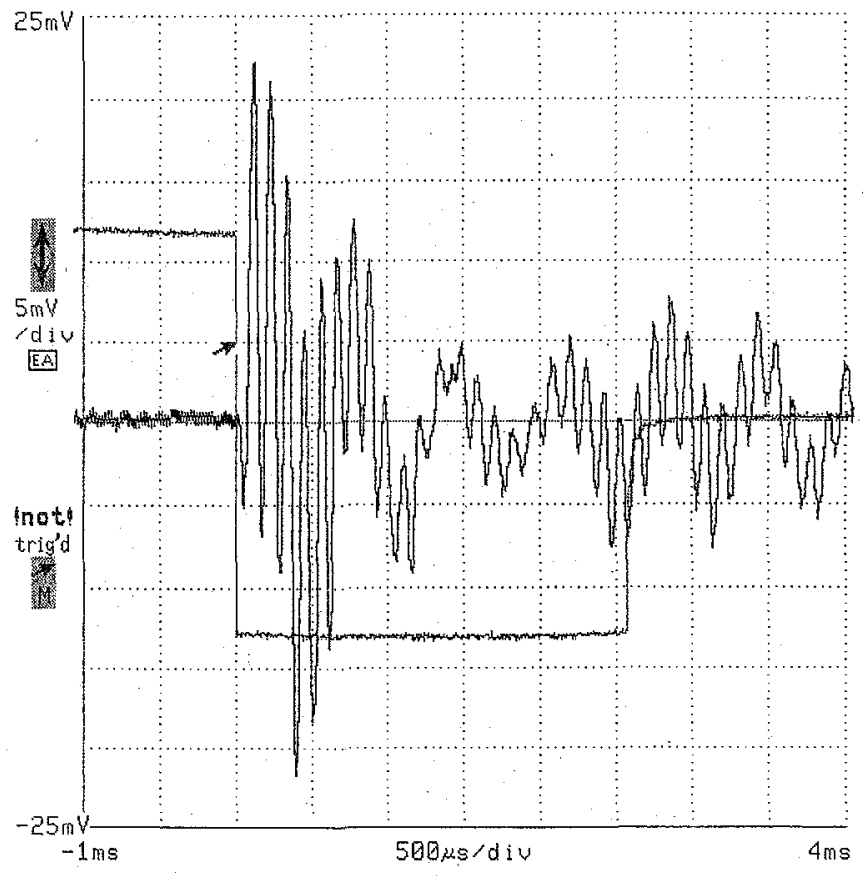

Fig. 2. Accelerometer response from stationary pulse test. Accelerometer is behind driven pole.

\section{B. Operating Noise}

Measurement of stator vibration was carried out while the SRM was loaded by an absorbing dynamometer adjusted to provide approximately constant load torque over the speed range. The SR drive was run in single-pulse mode (no current chopping) with constant commutation angles. Speed was adjusted by manually adjusting the dc bus voltage. The resulting flat-topped current waveform was approximately the same, except for frequency, for all load points in the tests. Stator vibration was measured with an accelerometer placed on the stator OD behind one of the stator poles.

It was noted earlier that the fundamental mode is excited when the natural frequency is an odd harmonic of the phase frequency. Fig. 6 shows the phase current, accelerometer output, and the fast Fourier transform (FFT) of the accelerometer output for a speed of $5430 \mathrm{r} / \mathrm{min}$. The "natural" SRM current waveform can be observed, with a peak value of approximately $5 \mathrm{~A}$. The phase frequency is $543 \mathrm{~Hz}$, and the high amplitude of vibration can be noted in the accelerometer output, shown in the middle trace of Fig. 6. The FFT of the accelerometer output is shown in the lower trace in Fig. 6, and clearly displays the dominant vibration at $1.6 \mathrm{kHz}$. It was observed by researchers in the laboratory that the noise of the SRM changed from a "growl" to a loud and clear whistle at about $1.6 \mathrm{kHz}$ as the speed was adjusted to near $5400 \mathrm{r} / \mathrm{min}$.

The vibration of the fundamental mode will be diminished when the natural frequency is an even harmonic of the phase frequency. Fig. 7 shows the experimental waveforms for operation at $3930 \mathrm{r} / \mathrm{min}$. It can be noted that the phase current has the same shape and amplitude as in Fig. 6. This is the result of adjusting speed by adjusting voltage while torque and commutation angles remain the same; hence the electromagnetic forces on the stator should be nearly the same in the two tests. The phase frequency is $393 \mathrm{~Hz}$, and the amplitude of the accelerometer output is substantially reduced compared with that of Fig. 6.

The FFT of the accelerometer output shows that the vibrations near $1.6 \mathrm{kHz}$ are greatly diminished. It may also be noted that there is more energy content near $8.7 \mathrm{kHz}$, which may correspond to the fourth-order mode of Fig. 1(d). It was noted above that the fourth-order mode will be excited when the mode frequency is one of the alternate even harmonics of the drive frequency; the $22 \mathrm{nd}$ harmonic of the $393-\mathrm{Hz}$ phase frequency is $8646 \mathrm{~Hz}$.

Researchers in the laboratory observed that the SRM was substantially quieter at $3930 \mathrm{r} / \mathrm{min}$ than at $5432 \mathrm{r} / \mathrm{min}$, even though the output torque and phase current were nearly identical. The reduction in observed noise is clearly due to the reduced contribution from the fundamental mode. Younger members of the team claimed to hear the $8.7 \mathrm{kHz}$ noise more clearly at the lower speeds.

\section{APPROXIMATE FORMULA FOR MODE FREQUENCY}

An approximate formula for the frequency of the fundamental mode is derived by modeling the stator lamination stack as a uniform cylindrical shell and invoking energy conservation principles to deduce the frequency.

\section{A. Potential Energy}

Consider the deflection of a plain ring subject to a vertical load W. Roark and Young. [14] give the change in vertical diameter as

$$
D_{v}=\frac{W \cdot R^{3}}{E \cdot I}\left(\frac{\pi}{4}-\frac{2}{\pi}\right)
$$

where $R$ is the ring radius, $E$ is the modulus of elasticity, and $I$ is the polar moment of inertia. The product $E \cdot I$, for a rectangular section of thickness $t$, length $L$, and Poisson ratio $\nu$, is given as

$$
E \cdot I=\frac{E t^{3} L}{12\left(1-\nu^{2}\right)}
$$

Substituting and reducing, using $\nu=0.3$, yields

$$
D_{v}=1.625\left(\frac{W}{L}\right) \frac{R^{3}}{t^{3}} \cdot \frac{1}{E}
$$

The "spring constant" per unit length may be defined as

$$
K=\frac{W / L}{D_{v}}=\frac{1}{1.625} \frac{t^{3}}{R^{3}} E
$$

Finally, defining the radial deflection as $\Delta=D v / 2$, one may express the potential energy per unit length as

$$
\text { P.E. }=\frac{2}{1.625} \frac{t^{3}}{R^{3}} E \cdot \Delta^{2}
$$




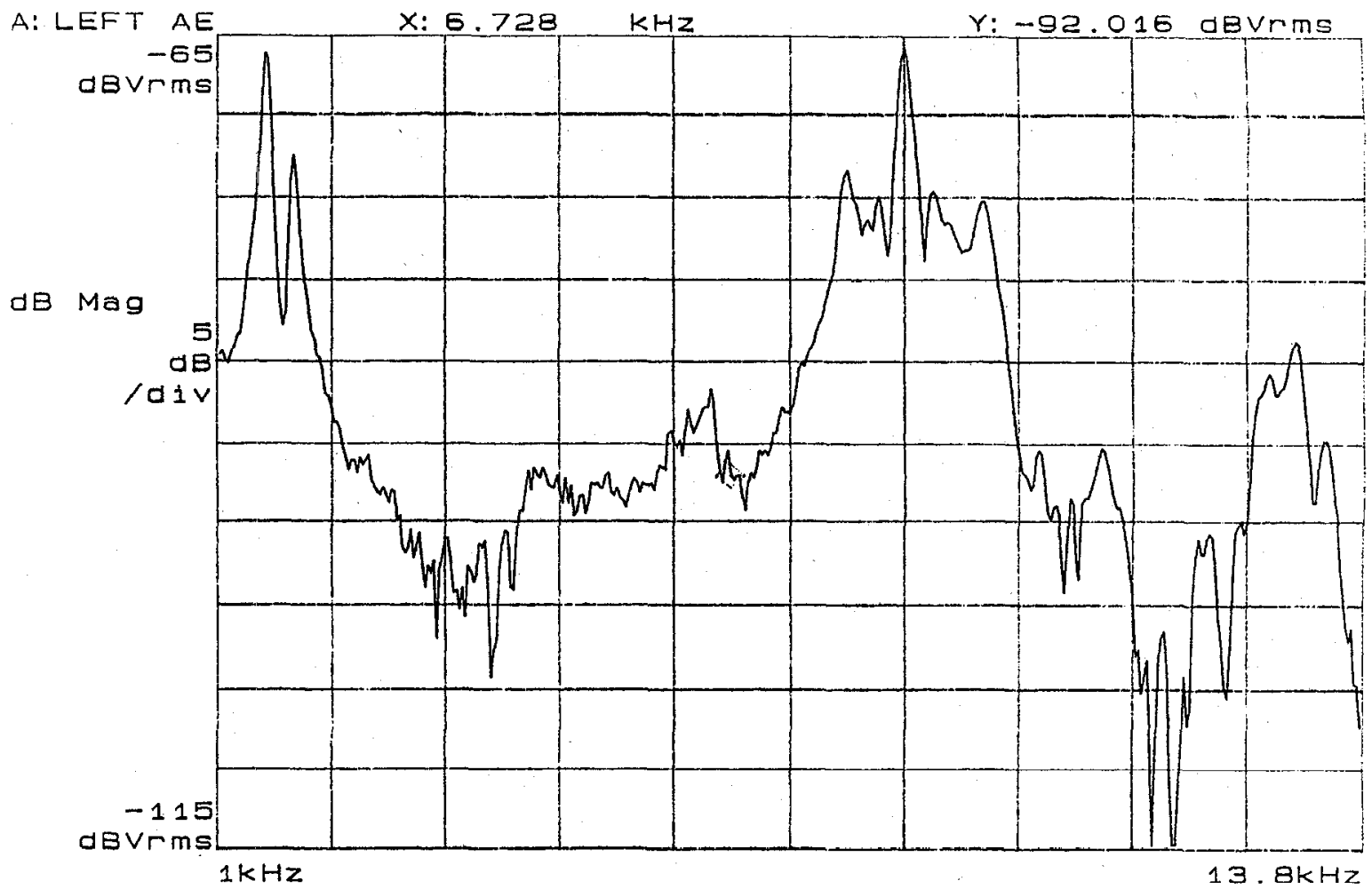

Fig. 3. Frequency spectrum from stationary pulse test. Accelerometer is behind driven pole.

\section{B. Kinetic Energy}

Assume that the ring is deformed into an ellipse with radius

$$
R(\theta)=R+\delta(t) \cos (2 \theta)
$$

and that the time variation of the radius is given by

$$
\delta(t)=\delta \sin (\omega t)
$$

The local velocity of a point on the ring is

$$
v=d R / d t=\omega \delta \cos (\omega t) \cos (2 \theta) .
$$

The kinetic energy of the entire ring is

$$
K E_{R}=\int_{0}^{2 \pi}[v \cdot R \cdot t \cdot L \cdot \rho] d \theta
$$

where $\rho$ is the mass density. Integrating and manipulating the resulting expressions gives the peak kinetic energy per unit length as

$$
\text { K.E. }=\rho \cdot t \cdot R \cdot \delta^{2} \cdot \pi \cdot \omega^{2}
$$

\section{Natural Frequency}

It is noted in Roark that the horizontal deflection $D_{H}$ of the ring is less than the vertical deflection $D_{V}$, and that $D_{V}=1.089 D_{H}$. Taking $\delta$ to be the average of the horizontal and vertical deflections yields

$$
\delta=\Delta / 1.0445 .
$$

Finally, equating kinetic energy (10) with potential energy (5) yields the resonant frequency

$$
\omega^{2}=\frac{2(1.0445)^{2}}{(1.625) \pi} \frac{E}{\rho} \frac{\dot{t}^{2}}{R^{4}} .
$$

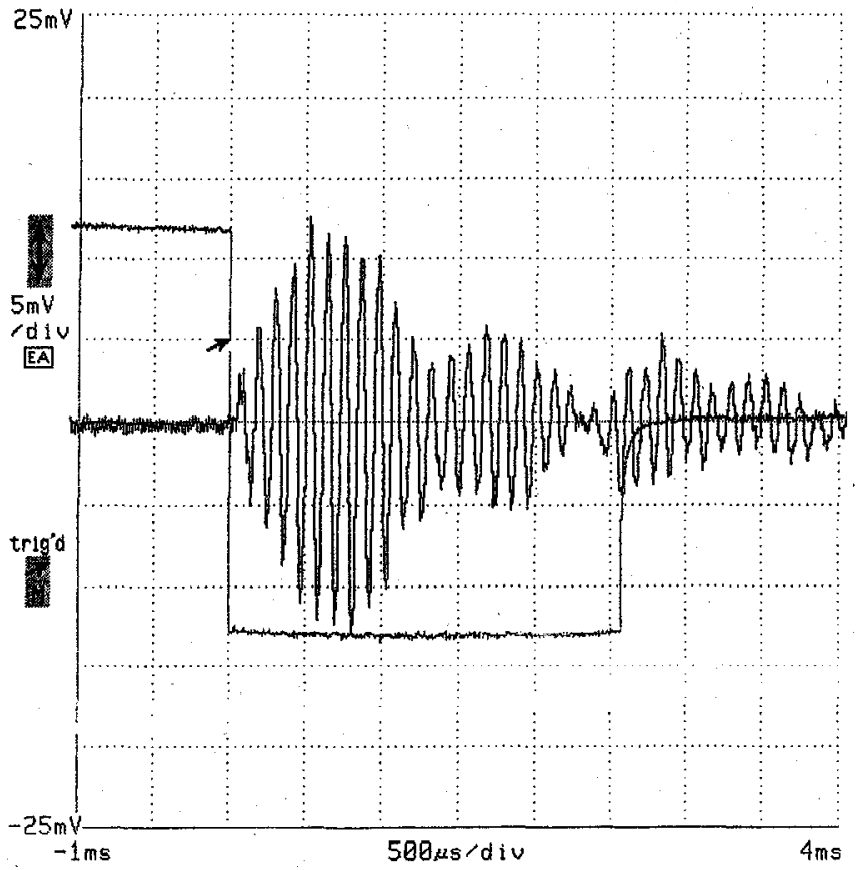

Fig. 4. Accelerometer response from stationary pulse test. Accelerometer is adjacent to driven pole.

A parametric study is employed to evaluate the formula (12). A FEA of an SRM lamination is conducted in which the yoke thickness is varied while the stator OD is held fixed at $160 \mathrm{~mm}$, and the bore diameter is $80 \mathrm{~mm}$. The geometric mean yoke radius is used in computing the mode frequency. The results are tabulated in Table I, along with 


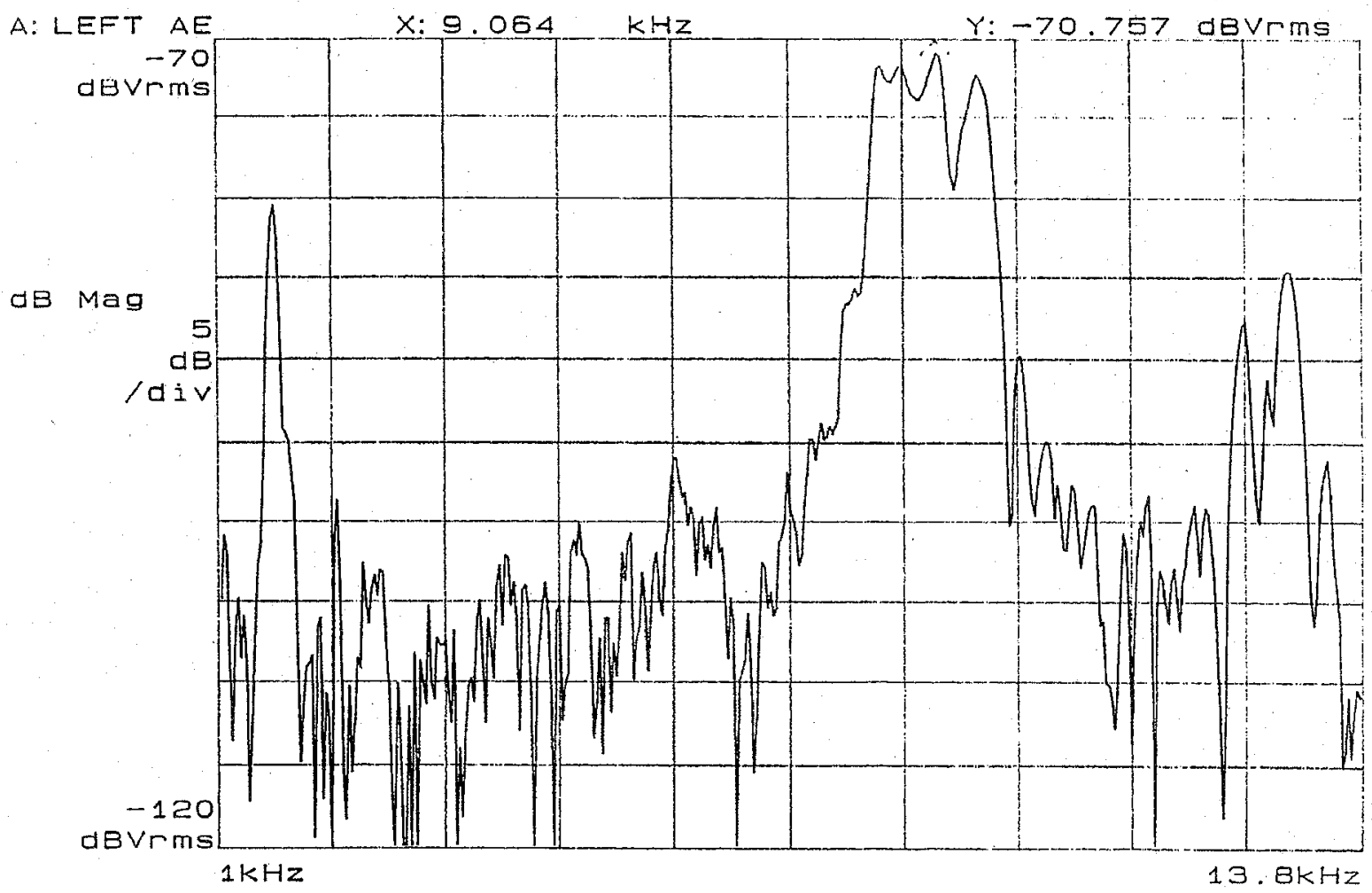

Fig. 5. Frequency spectrum from stationary pulse test. Accelerometer is adjacent to driven pole.

the estimate of the fundamental frequency of the actual SRM. The close agreement between the approximate formula and the FEA calculations shows that the formula may be used with confidence in design studies.

\section{DESIGN CONSIDERATIONS}

If all the methods for designing the SRM for low noise were known and could be analyzed by simple calculation, the design trade-offs would be easier to quantify, but this is sadly not the case. What follows is a partial account of some noise-reduction measures and a qualitative discussion of the trade-offs associated with them.

It is well known that the noise level of the SRM tends to increase with load. The obvious implication is that the noise level can be reduced by running the machine at light load, i.e., with lower flux densities and currents. The trade-off is a direct choice between adequate power density and low noise.

The stator yoke (back-iron) should be as thick as possible, with a large fillet radius at pole-root corners (where the pole joins the yoke); this radius is important on both stator and rotor. Clearly these measures decrease the available winding area in the stator slot, which tends to increase the current density and copper losses. Since most SRM's are copperloss-intensive, this trade-off is quite acute. A thicker yoke also increases the thermal diffusion distance for heat transfer from the windings to the outside frame. On the other hand, it decreases the flux density in the steel, which probably reduces both the core loss and the acoustic noise to a certain degree.

Notches and holes in the laminations are undesirable, since they may diminish the mechanical stiffness (unless carefully

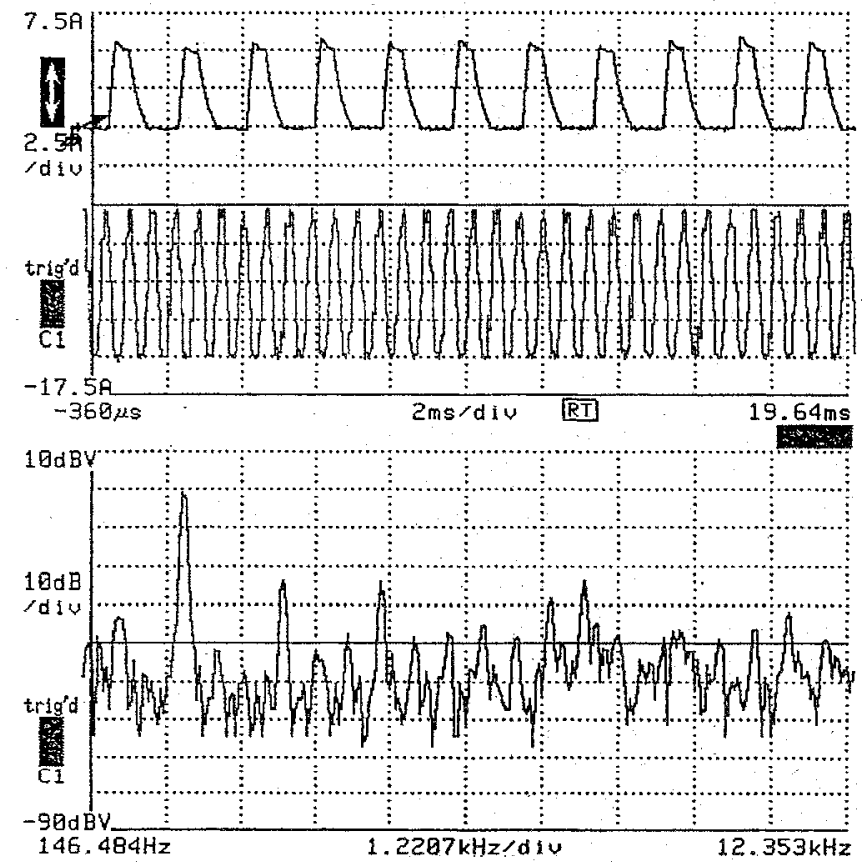

Fig. 6. Operation at $5430 \mathrm{r} / \mathrm{min}$. Upper: Current, $2.5 \mathrm{~A} /$ div.. Middle: Accelerometer, $100 \mathrm{mV} / \mathrm{div}$. Lower: FFT of accelerometer, $10 \mathrm{~dB} / \mathrm{div}$.

located), and they may produce local concentrations in magnetic flux density with a slight increase in magnetic noise.

Because of the nature of the SRM, with deep cut-outs on both sides of the airgap, the shaft diameter tends to be proportionally smaller than in induction motors or brushless PM motors, so that any residual unbalanced radial forces 


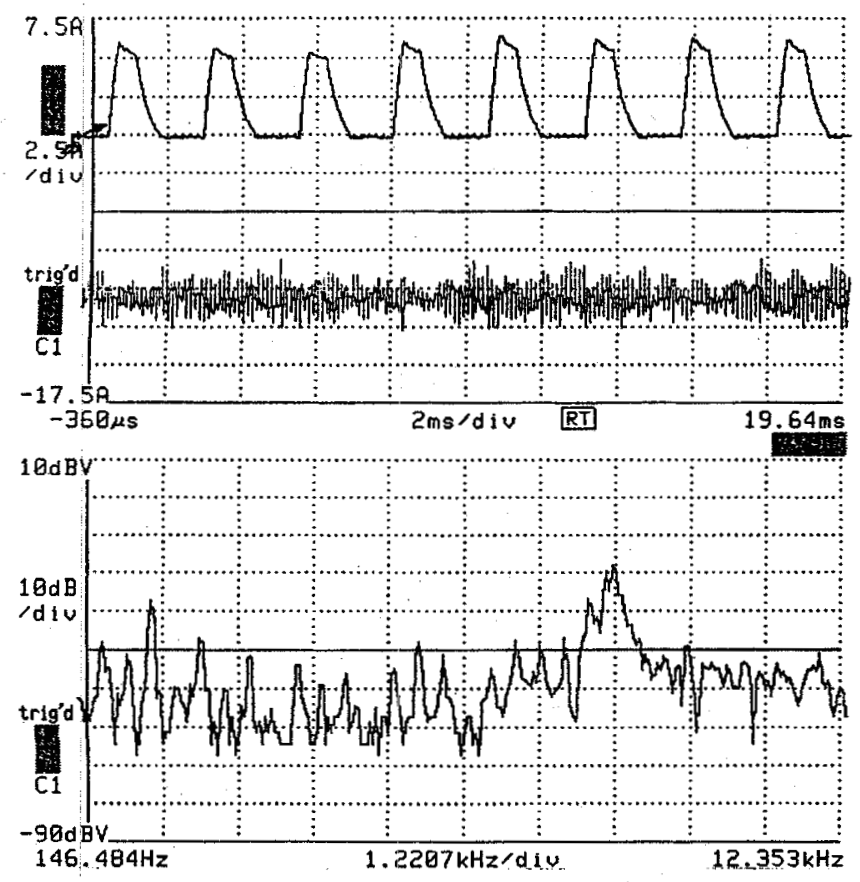

Fig. 7. Operation at $3930 \mathrm{r} / \mathrm{min}$. Upper: Current, $2.5 \mathrm{~A} / \mathrm{div}$. Middle: Accelerometer, $100 \mathrm{mV} / \mathrm{div}$. Lower: FFT of accelerometer, $10 \mathrm{~dB} / \mathrm{div}$.

TABLE I

COMPUTED MODE FREQUENCIES OF SRM Laminations

\begin{tabular}{|l|l|l|l|l|}
\hline \multicolumn{2}{|c|}{ Dimensions } & \multicolumn{2}{c|}{$\begin{array}{c}\text { Mode Frequency } \\
(\mathrm{Hz})\end{array}$} & Accuracy \\
\hline$O D(\mathrm{~mm})$ & Yoke (mm) & FEA & Eormula & Ratio \\
\hline 159.7 & 16.3 & 1679 & 1684 & 1.003 \\
\hline 160 & 14 & 1390 & 1388 & 1.001 \\
\hline 160 & 20 & 2300 & 2181 & 1.055 \\
\hline 160 & 26 & 3330 & 3150 & 1.057 \\
\hline
\end{tabular}

(which are always pulsed) can easily produce deflection and noise. The bearings should be located as close as possible to the rotor stack, if necessary by designing the bearing housings to protrude under the end windings. This feature is used in other types of motor to help maintain good concentricity and minimize lateral deflection of the rotor. The SRM is particularly sensitive to runout (eccentricity of the rotor), and for this reason a stiff bearing system is desirable, with tight tolerances on the airgap length and concentricity. It is questionable whether sleeve bearings can be used in SR motors without extremely careful design.

In punching it is important to ensure that the lamination are truly symmetric to avoid unbalanced radial forces. It is possible with some production methods to get angular errors in the pole locations: for example, two poles that are not exactly opposite. Punching drawings should always specify a tight tolerance on the angular dimensions of the poles.

Unbalanced radial forces can result from several other causes. Since they are pulsed and vary in repetition frequency, they do not need to be very large to excite mechanical resonances which produce deflections and acoustic noise.
Certain combinations of pole-number, phase-number, and coil winding polarity do not permit a completely balanced magnetic flux distribution: indeed one of these is the common $8 / 6$ fourphase SRM. A simple test of the electrical and magnetic balance is to measure the coil resistances and self and mutual inductances.

The airgap length is another parameter that is subject to an acute trade-off. Relatively small increases of airgap length help to reduce the acoustic noise, but a large airgap rapidly depletes the all-important inductance ratio by reducing the aligned inductance. It also tends to reduce the "squareness" of the magnetization curves, which decreases the torque per ampere and increases the reactive circulating current; this in turn increases the size of the required power transistors and diodes and the dc filter capacitor.

The noise producing forces are proportional to current or to current squared. While there is no possibility of discontinuity in the current itself, step-changes are frequent in the rate of change of current $d i / d t$, and these are liable to excite resonances, as recognized by $\mathrm{Wu}$ and Pollack [3]. A small airgap produces a rapid change of inductance and contributes to a large change in $d i / d t$ if there is significant current at the extremes of pole overlap. Ideally the second and all higher order derivatives of the current waveforms would be finite and small, since any of them can couple with mechanical eigenmodes, but this is not possible with the switchmode operation of power-electronic controls.

The controller should use voltage-pulsewidth modulation (PWM) with variable duty-cycle and a controlled chopping frequency, rather than a fixed-band current hysteresis regulation. This produces a marked reduction in noise level, without necessarily introducing any reduction in torque per rms ampere, although the torque ripple may increase slightly. The phase current should be regulated by chopping only one transistor, not both. This way, there is lower current ripple and the freewheel mode caused by this "soft chopping" creates only half the change in $d i / d t$ as switching both transistors. It is even better to use a phase controlled rectifier or a single dc chopper, and only use the phase transistors for commutation and controlling the firing angles.

\section{CONCLUSIONS}

Structural FEA has been used to compute the eigenmodes of the 4-phase SRM lamination. Measurement of vibration during impulse tests and during operation under load confirms the accuracy of the FEA calculations and demonstrates that structural FEA can be useful in studying the vibration modes of a specific lamination design. Heuristic arguments are presented to show what operating conditions excite the dominant eigenmodes. These conditions are confirmed by experiment.

An approximate formula is derived to predict the frequency of the dominant eigenmode. The formula is shown to be accurate by comparison with structural FEA, and hence is useful in preliminary design studies to evaluate the impact of parameter changes on acoustic noise. A discussion of design considerations highlights some of the trade-offs involved in designing and manufacturing a low-noise SRM. 


\section{REFERENCES}

[1] B. D. Bedford, U.S. Patents 3678352 and $3679953,1972$.

[2] P. J. Lawrenson et al., "Variable speed switched reluctance motors," Proc. Inst. Elect. Eng., vol. 127, pt. B, pp. 253-266, 1980.

[3] D. E. Cameron, J. H. Lang, and S. D. Umans, "The origin and reduction of acoustic noise in doubly salient variable reluctance motor," IEEE Trans. Ind. Applicat., vol. 26, pp. 1250-1255, 1992.

[4] C. Y. Wu and C. Pollock, "Time domain analysis of vibration and acoustic noise in the switched reluctance drive," in IEE 1993 Int. Conf. Electric Machines and Drives, pp. 558-563.

[5] F. Blaabjerg, P. Nielsen, L. Andersen, and P. C. Kjaer, "Investigation and reduction of acoustical noise from switched reluctance drives in current and yoltage control," in Int. Conf. Electrical Machines, (ICEM'94), Paris, France, Sept. 5-8, 1994, pp 3.589-3.594.

[6] J.-Y. le Chenadec, M. Geoffroy, B. Multon, and J.-C. Mouchoux, "Torque ripple minimization in switched reluctance motors by optimization of current wave-forms and of tooth shape with copper losses and "V.A. Silicon" constraints," in lnt. Conf. Electrical Machines, (ICEM'94), Paris, France, Sept. 5-8, 1994, pp 3.559-3.564.

[7] J. V. Byrne, "Tangential forces in overlapped pole geometries incorporating ideally saturable material," IEEE Trans. Magn., vol. MAG-8, pp. $2-9,1972$.

[8] K. Takayama et al., "Thrust force distribution on the surface of stator and rotor poles of switched reluctance motor," IEEE Trans. Magn., vol. 25, pp. 3997-3999, Sept. 1989.

[9] J. R. Hendershot, "Causes and sources of audible noise in electric motors," in Proc. 22nd Incremental Motion Control Systems and Devices Symposium, B.C. Kuo, Ed., Champaign, IL, June 8, 1993, pp 259-270.

[10] T. J. E. Miller, "Faults and unbalanced forces in the switched reluctance machine," in 1993 IEEE 28th Industry Applications Society Annual Meeting Conf. Rec., 93CH3366-2, pp. 87-96.

[11] E. C. T. So, R. G. D. Williams, and S. J. Yang, "A simple model to calculate the stator radial vibration of a hybrid stepping motor," in 1993 IEEE 28th Industry Applications Society Annual Meeting Conf. Rec., 93CH3366-2, pp. 122-129.

[12] C. Y: Wu and C. Pollock, "Analysis and reduction of acoustic noise in the switched reluctance drive," in 1993 IEEE 28th Industry-Applications Society Annual Meeting Conf. Rec., pp 106-113.

[13] M. Besbes, Z. Ren, A. Razek, and S. Allano, "Vibration diagnostic for doubly salient variable relucatance motors," in Int. Conf. Electrical Machines, (ICEM'94), Paris, France, Sept. 5-8, 1994, pp 3.415-3.418.

[14] Roark and Young, Formulas for Stress and Strain, 5th ed. New York: MeGraw-Hill, 1982, Art. 8.3.

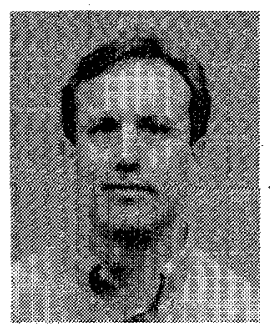

Roy S. Colby (S'82-M'87-SM'94) is a native of Cincinnati, OH. He received the B.S. degtee from the Massachusetts Institute of 'Technology, Cambridge, in 1978, and the Ph.D. degree in 1987 from the University of Wisconsin, Madison, where he cofounded the WEMPEC Symposium, and wrote an IAS committee first prize paper on PM synchronous motor drives.

After working in industry for several years prior to undertaking graduate studies and a brief period as a college professor, he joined United Technologies Corporation (UTC), East Hartford, CT, in 1990. Since then he has held various assignments in research and product development for the UTC automotive, elevator, air conditioning, and aerospace businesses. He is currently a Principal Engineer with Otis Elevator, a UTC company, where he is engaged in the application and development of ac drives for traction elevators. He holds one U.S. patent in elevator control technology, with others pending, and has authored or coauthored over a dozen technical papers in the subjects of electric machines and motor drives:

Dr. Colby has served as Associate Editor of the IEEE TRANSACTIONS ON POWER ELECTRONICS, and as the Secretary of the IAS Electric Machines Committee

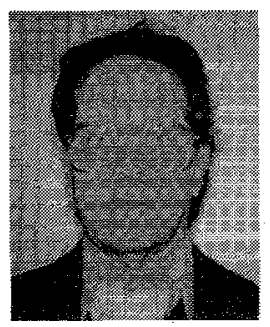

François M. Mottier is a native of Switzerland. He received the diploma in 1966 from the Swiss Federal Institute of Technology, in Zurich, Switzerland, and the $\mathrm{Ph} . \mathrm{D}$. degree from the University of Berne, Berne, Switzerland.

From 1966 to 1976 he was a scientific staff member at the Brown, Boveri Research Center in Dättwil, Switzerland, where he performed original research in the fields of electrooptics, holography, and speckle interferometry. From 1976 to 1995 , he was a senior project engineer at United Technologies Research Center, East Hartford, CT, where his work centered on infrared optics, image processing, acoustic noise reduction, and the development of a traveling wave ultrasonic motor. His contribution to the development of an automatic motion analysis system for clinical use has earned him wide recognition. He has 34 patents and numerous publications to his credit. In 1995, he started an independent consulting company for electrooptic and general mechanical developments. In that capacity he has recently also entered the field of sea water desalination.

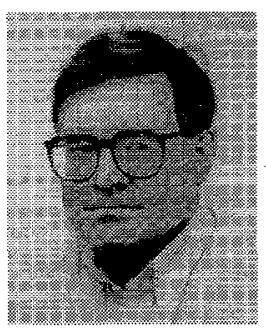

Timothy J. E. Miller (M'74-SM'82-F'96) is a native of Wigan, U.K. He was educated at Atlantic College, and received the B.Sc. degree from the University of Glasgow and the Ph.D. degree from the University of Leeds.

$\mathrm{He}$ is currently Lucas Professor in Power Electronics, and founder and Director of the SPEED Consortium, University of Glasgow. Scotland, where he is responsible for teaching and research in power electronics and electrical power engineering. The SPEED Laboratory serves some 35 industrial companies in the U.K., USA, Europe, and the Far East with design software for electric motor design; and with special electronic controls and development equipment for motor drive systems. From 1979 to 1986, he was an electrical engineer and program manager at General Electric Corporate Research and Development, Schenectady, NY, and his industrial experience includes periods with GEC (U.K.), British Gas, International Research and Development, and a student-apprenticeship with Tube Investments Ltd. He is the author of 105 publications in the fields of motors, drives, power systems, and power electronics, including five books.

Dr. Miller is a Fellow of the Royal Society of Edinburgh and the Institution of Electrical Engineers. 